\title{
Effectiveness of Public versus Private Ownership: Violations of the Safe Drinking Water Act (SDWA)
}

\author{
Guanlong Fu, Pengfei Liu $\odot$, and Stephen K. Swallow
}

\begin{abstract}
The relative performance of public and private enterprises has been long debated. We construct a comprehensive violation dataset based on the EPA's Safe Drinking Water Information System to empirically investigate the compliance behavior of publicly and privately owned Public Water Systems (PWSs). Our results show that publicly owned PWSs commit significantly more Maximum Contamination Level, Treatment Technique, and Health-Related violations but fewer Monitor and Reporting violations than privately owned PWSs. We also find that municipal-level heterogeneities explain a substantial amount of variation in violation behaviors among PWSs, suggesting water supply quality depends crucially on location-specific regulations and local economic conditions.
\end{abstract}

Keywords: Safe Drinking Water Act, Public Utilities, Private Utilities, Water Quality, Violations

\section{Introduction}

Water utility privatization in the early 1980s raises concern about whether privately owned Public Water Systems (PWSs) can outperform publicly owned utilities (Arnold 2009). Competition is limited in the water utility industry. Huge capital intensity creates a natural monopoly and a high barrier to enter the water utility industry. The National Research Council (2002) reports that "measured by the ratio of net utility plant capital costs to annual operating revenues, water utilities are more than twice as capital-intensive as the second-most capital-intensive utility sector, electricity." Although publicly owned enterprises may resolve market failures, they have objectives other than profit maximization, such as public responsibility and political considerations. Thus, publicly owned enterprises may not achieve full economic efficiency (Meginnson and Netter 2001). Privately owned water systems may be more rigorously managed for cost minimization or profit maximization, while publicly owned facilities might be more sensitive to

Guanlong Fu, PhD Candidate, Department of Agricultural and Resource Economics, University of Connecticut. Email: guanlong.fu@uconn.edu. Pengfei Liu, Assistant Professor, Department of Environmental and Natural Resource Economics, University of Rhode Island. Stephen K. Swallow, Professor, Department of Agricultural and Resource Economics, Center for Environmental Sciences and Engineering, University of Connecticut. Email: Stephen.swallow@ uconn.edu. Correspondence: Pengfei Liu, Assistant Professor, Department of Environmental and Natural Resource Economics, University of Rhode Island. Email: pengfei_liu@uri.edu

Agricultural and Resource Economics Review 49/2 (August 2020) 291-320

(C) The Author(s) 2020. This is an Open Access article, distributed under the terms of the Creative

Commons Attribution licence (http://creativecommons.org/licenses/by/4.0/), which permits unrestricted re-use, distribution, and reproduction in any medium, provided the original work is 
politically based pressures and the perceptions stimulating public reactions. Publicly owned enterprises also rely more on public funds and face more financial challenges in poor municipalities. In addition, managers of publicly owned firms may have opportunities to increase their own welfare at the expense of the employees and tend to make input choices favoring short-run benefits during their tenures as managers (Crain, Mark, Zardkoohi 1978).

With distinct incentives driven by the ownership context, we might expect different performance on various indicators important to achieving the objectives of the PWS in the public interest. For example, incentives and employee (or management) response could affect the quality of water delivered by drinking water systems. Therefore, privately owned facilities are expected to have an increase in Monitor and Reporting (MR) violations, as these might offer the opportunity to avoid or delay the costs of responding to a Maximum Contamination Level (MCL) violation, and privately owned facilities may be inclined to delay compliance with a Treatment Technique (TT) regulation that imposes a costly new technology. In contrast, a publicly owned facility may be particularly sensitive to the public health - and therefore public protest implications of MCL events - or perhaps be relatively more compliant with MR regulations because any violation could lead to politically costly public response. ${ }^{1}$ Our article qualitatively outlines some of the incentives that could affect the performance of a public service agent, using the context of drinking water delivery under the U.S. Safe Drinking Water Act (SDWA). We also evaluate whether publicly and privately owned PWSs perform differently in several different categories of regulatory violations relative to the SDWA.

To establish a credible relationship, we build a comprehensive dataset including over 2 million drinking water violation records linked with PWS characteristics to investigate the relationship between drinking water violations and PWS ownership types. We address the potential confounding factors using a set of fixed effects models controlling for the state-level or the municipality-level heterogeneities. We provide strong empirical evidence that publicly owned PWSs commit significantly more Maximum Contamination Level (MCL) and Treatment Technique (TT) violations but fewer Monitor and Reporting (MR) violations than privately owned PWSs. As already mentioned, publicly and privately owned utilities have different objective functions, and the privately owned utilities may choose low-cost compliance actions to avoid high-cost actions, which is consistent with the empirical results where the privately owned PWSs tend to commit more MR violations while avoiding potentially more expensive MCL, TT, and Health-Related violations. Our results provide new insights on the long-debated relative advantages of

\footnotetext{
1 According to the EPA, National Primary Drinking Water Regulations (NPDWR) require PWSs to conduct public notification once they are in violation so that the violations can be visible to the public quickly.
} 
private and public utilities in the water supply industry. This study also contributes to a broadly interesting question about whether ownership affects public health or creates political incentives that can be seen to both affect public service outcomes and contribute to the discussion of the potential roles of the public sector, private companies, and communities in the drinking water supply market (Bakker 2014).

\section{Literature Review}

Results on economic performance of privately and publicly owned utilities. Several factors are identified that affect the cost of private and public water utilities. Profit margin requirements, dividends, and income tax usually add up to 20-30 percent of private utilities' operation and maintenance costs (Food \& Water Watch 2015). Public utilities' attention to health contributes to overstaffing or overdesigning, resulting in cost increases (Wolff and Hallstein 2005). Suárez-Varela et al. (2017) use directional distance functions, metafrontiers, and Data Envelopment Analysis to assess efficiency performance in 70 municipalities in Spain. They find private management is more efficient in the application of labor input but less efficient at managing operating costs. Saal and Parker (2001) find that productivity growth has not improved since the privatization trend of the water and sewage industry in England and Wales started in 1989, though output price outgrows the input costs due to the profit increase following privatization. Crain and Zardkoohi (1978) estimate a log-linear cost function of labor and capital input controlling for the ownership type. They find that labor productivity in public water firms is low compared to private water firms, and the capital-labor ratio doubled in public water utilities when the public utility switched to private ownership, implying an increase in economic efficiency.

Data acquired by non-profit organizations have been used to quantify the difference between public and private water facilities. Feigenbaum and Teeples (1983) estimate a hedonic cost function based on data from the American Water Works Association (AWWA) for 57 private and 262 public water companies in 1970. Results suggest no statistically significant differences in parameter estimates between public and private utility companies. Similarly, Byrnes, Grosskopf, and Hayes (1986) use a linear programming approach using data from the AWWA for 59 private and 68 public water companies to calculate the technical and scale efficiency. They found no significant differences in efficiency across ownership types. Teeples and Glyer (1987) generalize Feigenbaum and Teeples's (1983) model by disaggregating input categories and controlling for additional interaction terms. Results suggest that overall efficiency differences are insignificant in the generalized model. Bhattacharyya et al. (1995) use a stochastic frontier cost function to estimate the cost of the inefficiency for both public and private water utilities and find that private water utilities are more efficient with a small operation scale, while public water utilities are more efficient 
with a large-scale operation, possibly due to private water utilities being relatively more cost burdened while scaling up production.

Other empirical efforts devoted to comparing the price performance show that privately operated or owned water utilities usually charge significantly higher water prices to their customers. Porcher (2017) uses a unique dataset of water utilities with detailed financial indicators (e.g., water utility debt) and finds that private water utility management is associated with higher water rates than their public counterparts. However, the price difference disappears when public water utility debt is taken into consideration, since debt refunding of the public service could increase the price in the following years. Chong et al. (2006) employ a switching regression model with a database of 5,000 French local public authorities and find that the choice of water utility ownership made by local authorities is not random and that a Public-Private partnership on average charges a higher water price than either publicly or privately owned utilities. Similarly, Wait and Petrie (2017) and Garcia-Valiñas et al. (2013) find that privately owned water utilities have a higher price of water in the United States and France, respectively.

There are only a few studies comparing water supply quality between publicly and privately owned water utilities. Food \& Water Watch (2015) suggests that, even though facing the same degree of regulation, private operators attempt to cut costs by using shoddy construction materials, delaying needed maintenance, or downsizing the workforce, which impairs customer service and slows responses to emergencies, while public system managers have the incentive to provide high water quality, care about public health, and care about environmental quality as well as associated values (Wolff and Hallstein 2005). Rahman et al. (2010) identify the characteristics of PWSs contributing to the violation of MCL standards based on the SDWA data for 971 PWSs in Arizona. They find that publicly owned PWSs have a slightly higher probability of violating MCL standards than privately owned systems. Allaire $\mathrm{Wu}$, and Lall (2018) use probit regression and principal component analysis with U.S. EPA's Safe Drinking Water Information System (SDWIS) violations data and water system characteristic data across the United States from 1982 to 2017. They also find that privately owned PWSs are associated with a lower rate of MCL compliance.

While the results just stated indicate privately owned PWSs are associated with fewer MCL violations, this result might be misleading, as there are several other types of violations. Some PWSs can commit less costly violations (such as MR) to avoid expensive violations (such as MCL). ${ }^{2}$ We find qualitative evidence of strategic or underreporting behaviors for privately owned utilities in the SDWIS dataset in the comment section. With careful review of the comment section of MR violations, we observe that a

2 More details regarding the cost of different types of violations will be provided later in this section. 
substantial number of privately owned PWSs with MR violations missed the required sample and never submit the missed sample later to their primacy agencies. Thus, we looked at several major types of violations to get a full understanding of the relationship between ownership and types of violations.

Existing research also suggests several factors potentially influence both ownership and water quality violations. For example, Troesken and Geddes (2003) argued that strict local regulations and high transaction costs are the cause of water system municipalization at the turn of the $20^{\text {th }}$ century. Arnold (2009) states that long overdue or delayed investment in infrastructure in water utilities owned by many municipalities in degenerate financial situation leads to privatization, aging facilities, and obsolete services. Wallsten and Kosec (2008) study the relationship between violation types and PWS ownership types, but they fail to fully control local heterogeneities that may influence both water quality violation and ownership types.

\section{Background}

Drinking water quality can be critical to public health. Congress passed the Safe Drinking Water Act (SDWA) in 1974 and amendments in 1986 and 1996 to protect the nation's public drinking water supply. Under the SDWA, the U.S. EPA promulgated National Primary Drinking Water Regulations (NPDWR) (U.S. Government Publishing Office 2019) to set standards and treatment techniques for more than 90 contaminants (Tiemann 2017). The NPDWR applies to over 170,000 public water systems (PWSs) that are identified as having at least 15 service connections or serving at least 25 people per day for 60 days of the year (Office of Water, U.S. EPA 2004). EPA usually authorizes states and Indian tribes to assume primary oversight for PWSs to enforce NPDWR. PWSs should monitor regulated contaminants in their water supply and report monitoring results to their primacy agencies in order to be determined as in compliance under NPDWR (Tiemann 2017). PWSs' violations may lead to enforcement actions such as administrative orders, financial penalties, and civil actions against PWSs.

Despite established regulations, improper disposal of chemicals, animal wastes, pesticides, fertilizers, wastes injected to groundwater, and naturally occurring substances can all contaminate drinking water (Office of Water, U.S. EPA 2004). For example, the natural occurrence of a moderate to a high level of arsenic in groundwater is common in western states (Welch, Lico, and Hughes 1988). EPA's National Water Quality Inventory (2017) reports that 46 percent of river and stream miles are in poor biological condition and 21 percent of the nation's lakes are hypereutrophic (i.e., with the highest levels of nutrients, algae, and plants), where phosphorus and nitrogen are the most widespread stressors in rivers and lakes. Moreover, enforcement failure, improper treatment, and poorly maintained distribution systems can adversely affect drinking water quality (Office of Water, EPA 2004). The Flint 
water crisis is a result of improper treatment and failures at multiple levels of government (Butler, Scammell, and Benson 2016). The lead crisis in Washington, DC, in 2001 is a result of the reaction between old lead pipes and new treatment chemicals applied by the plant to comply with the Disinfection Byproducts Rule (Renner 2004). Compliance issues also persist and may negatively impact drinking water quality. The U.S. EPA Office of Enforcement and Compliance Assurance (2013) national public water systems compliance report finds that MR violation is the dominant violation type, indicating a large number of PWSs fail to meet monitoring and reporting frequency rules for the drinking water quality during applicable compliance periods.

Small PWSs are more likely to violate NPDWRs, due to a lack of resources to conduct proper operation and maintenance. The U.S. EPA Office of Enforcement and Compliance Assurance (2013) national public water systems compliance report suggests that noncompliance occurs more frequently in small PWSs, despite EPA's and states' efforts to develop financial and operational programs to assist small PWSs to achieve better compliance. Rubin (2013) reports summary statistics based on the U.S. EPA data for violations by community water systems (CWSs). Results show that small water systems are more likely to violate health-related requirements than large systems. Guerrero-Preston et al. (2008) use a small sample of CWSs over a five-year period to identify non-compliance with drinking water standards in Puerto Rico. They found that most small rural systems in Puerto Rico were noncompliant with NPDWRs during the study period.

PWSs serving low-income and minority communities are more likely to violate NPDWRs. Balazs et al. (2011) combine water quality monitoring datasets (1999-2001), source location, and census block group data in California to study the relationship between CWSs' nitrate levels and socioeconomic status of the population served. They find that in smaller water systems, CWSs serving larger percentages of Latinos and renters receive drinking water with higher nitrate levels. Balazs et al. (2012) find similar conclusions in terms of arsenic MCL violations in the same study area. Pilley et al. (2009) evaluate the applicability of the Promotora Model in Dona Ana County in New Mexico, where arsenic levels in southern New Mexico are significantly higher than EPA-designated MCL. The Environmental Justice Coalition for Water (2005) reports that counties with a high Latino population have more drinking water violations in California.

Monitoring requirements and violation determinations are different among contaminants under SDWA and NPDWR (U.S. Government Publishing Office 2019). For inorganic chemicals such as arsenic, annual samples must be taken for surface water PWSs and triennial samples must be taken for groundwater PWSs. A PWS is in violation if the sampled contaminant exceeds the MCL standard set by EPA. PWSs with MCL violations must increase monitoring or sampling frequency to quarterly, and the violation is determined based on the annual average of all quarterly samples. For total 
coliform, the number of required routine samples are based on population served and must be taken at regular intervals each month at representative sites across every PWS. If a routine sample is total coliform positive, a PWS must take and analyze one repeat sample at the same tap as the original sample, and at a location within five connections both upstream and downstream within one day.

Violations are also dependent on the sampling frequency. A PWS taking fewer than 40 samples per month is in violation if two or more of their routine and repeat samples per month are total coliform-positive. A PWS taking more than 40 samples per month is in violation if more than five percent of routine and repeat samples per month are total coliform-positive. Stage one disinfection byproducts ${ }^{3}$ are mostly monitored quarterly, and the MCL violation is based on the running annual average of all quarterly samples. For most of the contaminants, failure to monitor, failure to monitor at a specified frequency, and failure to report the testing measurement on time are regarded as MR violations by the state and the EPA.

In lieu of an MCL, NPDWR specifies treatment techniques for specific biological pathogens (giardia lamblia, viruses, heterotrophic plate count bacteria, Legionella) and turbidity. Filtration and disinfection are required to be installed and properly operated to reliably achieve at least 99.9 percent removal or inactivation of Giardia lamblia, 99.99 percent removal or inactivation of viruses, fecal coliform concentration no greater than 20/100 $\mathrm{ml}$, and turbidity level no greater 5 NTU. ${ }^{4}$ Failure to properly install filtration and disinfection or failure to achieve the above substance level will result in a treatment technique violation. NPDWR also specifies treatment techniques for lead and copper instead of an MCL. Small (serving $<3,300$ persons) and medium systems (serving 3,300-50,000 persons) with lead and copper action level exceedance and all large PWSs shall install the optimal corrosion control treatment steps within the specified time frame or they are in violation of treatment techniques regulations.

All PWSs already applying optimizing corrosion control treatment shall monitor water quality parameters designated by the state and will be in treatment technique (TT) violations if they have an deviation for any parameters on more than nine days during each six-month monitoring period. EPA specifies treatment techniques for certain contaminants that have MCL designations, such as total organic carbon (TOC) in stage 1

\footnotetext{
3 The Stage 1 Disinfectants and Disinfection Byproducts (DBP) Rule reduces drinking water exposure to disinfection byproducts. The Rule applies to community water systems and nontransient, non-community systems, including those serving fewer than 10,000 people that add a disinfectant to the drinking water during any part of the treatment process. For more information, please see https://www.epa.gov/dwreginfo/stage-1-and-stage-2-disinfectants-anddisinfection-byproducts-rules\#rule-summary.

4 The units of turbidity from a calibrated nephelometer are called Nephelometric Turbidity Units (NTU).
} 
Disinfectants and Disinfection Byproducts (DBP). NPDWR requires PWSs using conventional filtration treatment to remove specific percentages of TOC that may react with disinfectants to form DBPs. Removal must be achieved through a treatment technique (enhanced coagulation or enhanced softening) unless a system meets alternative criteria.

The cost to comply with MCL and TT regulation is much higher than for MR violations. As described earlier, complying with MCL and TT regulations requires good maintenance of the water facilities, proper application of the treatment process, and appropriate operation of water facility staff, while complying with MR regulations only requires a PWS to regularly take and report samples. State agencies and the EPA can conduct formal enforcement actions such as an administrative order, a judicial referral, or a civil penalty, as well as informal actions such as issuing a violation notice, requiring public notification, and bilateral agreement (U.S. EPA 1986). Although U.S. EPA (1986) only specified the general principle of choosing the appropriate enforcement response, stronger enforcement action is usually conducted for severe health-based MCL violations and weaker enforcement actions are applied to MR violations. In the case of MCL violations, the state may issue administrative orders that require a PWS to hire engineers to conduct a feasibility study and a sanitary survey; PWSs may also be required to conduct new construction or replace parts of their pipes. However, the state might issue administrative orders that only require a PWS committing a MR violation to submit the missed sample.

The enforcement dataset of SDWIS shows that the percentage of state administrative orders is more frequent in MCL violations compared to MR violations (8.83 percent versus 4.03 percent), suggesting stricter enforcement of MCL violations. Interestingly, the percentage of "back to compliance" is smaller in MCL violations than it is for MR violations (24.33 percent versus 35.90 percent), indicating that MR violations may be relatively easy to fix, while MCL violations are more difficult to resolve. Furthermore, MCL and TT violations require, respectively, Tier 1 and Tier 2 public notices, while MR violations only require Tier 3 notice, which is considered less important and less urgent. ${ }^{5}$

In summary, the cost of compliance for MCL, TT, and MR violation regulation varies greatly. Since publicly and privately owned PWSs have distinct objectives and face possible differences in the cost of compliance with the three types of regulations, different types of PWSs are likely to commit one type of violation instead of others when water quality problems arise. We now provide a brief description of our dataset used in the empirical model.

\footnotetext{
5 Tier 1 public notice rule requires that the PWS in a situation that might impact human health must notify the potential affected population immediately, usually within less than 24 hours. Tier 2 requires notice as soon as possible, usually in 30 days. Tier 3 requires notice annually.
} 
Table 1. Summary Statistics of the Water System Ownership

\begin{tabular}{lrr}
\hline Owner Type & Freq. & Percent \\
\hline Federal Government & 10,937 & $2.95 \%$ \\
Local Government & 52,361 & $14.13 \%$ \\
Public/Private & 16,992 & $4.59 \%$ \\
Native American & 1,636 & $0.44 \%$ \\
Private & 275,989 & $74.48 \%$ \\
State Government & 12,647 & $3.41 \%$ \\
Total & 370,562 & 100 \\
\hline
\end{tabular}

Note: Table 1 lists the frequency distribution of PWSs by ownership types. Based on the 370,562 PWS in our sample, private is the dominant ownership type, accounting for 275,989 observations, followed by three public ownership types: local government, state government, and federal government amounting to $52,361,12,647$, and 10,937 PWSs, respectively. The co-ownership type, Public/Private takes about 16,992 PWS, and the least amount of PWSs is owned by Native Americans.

\section{Data Description}

Our data are acquired from the EPA's Safe Drinking Water Information System (SDWIS), maintained by the EPA Office of Ground Water and Drinking Water. The SDWIS tracks drinking water contamination levels as required by the 1974 Safe Drinking Water Act and subsequent amendments. The SDWIS also contains information about water system characteristics and violations of EPA's drinking water regulations.

Our water system dataset stores inventory information about 423,469 PWSs, including the type and ownership, city, county, population served, the number of connections, main water source, whether it is a water wholesaler, whether it is primarily serving a daycare, and primacy agency type. We use 370,562 observations for our sample (about 87.51 percent of the total database), for which we have data on the ownership type. Table 1 lists the types of PWSs by ownership. There are six different types of ownership recorded, with the private ownership being the majority type in our sample. We are able to identify 275,989 PWSs of private ownership, representing about 74.48 percent of the total sample. The PWS characteristics are combined with the violation information to construct a panel data used in the regression model. The local government ownership represents 14.13 percent of the total sample, followed by the public-private co-ownership type, which incorporates about 4.59 percent of the total PWSs in our sample. State and federal government ownership types represent about 3.41 percent and 2.95 percent, respectively. Only about 0.44 percent of the PWSs are owned by Native American entities.

We generate a set of ownership dummy variables for each ownership category. We define the dummy Public to include the federal government, 
Table 2. Water System Ownership and Scale

\begin{tabular}{lccc}
\hline & Small \& Medium & Large & Total \\
\hline \multirow{2}{*}{ Private } & 294,433 & 184 & 294,617 \\
& $99.94 \%$ & $0.06 \%$ & $79.51 \%$ \\
Public & 74,989 & 956 & 75,945 \\
& $98.74 \%$ & $1.26 \%$ & $20.49 \%$ \\
Total & 369,422 & 1,140 & 370,562 \\
& $99.69 \%$ & $0.31 \%$ & $100 \%$ \\
\hline
\end{tabular}

Note: Table 2 illustrates the relationship between PWSs' ownership type and scale. The numbers below counts are percentages. Large PWSs are the ones serving more than 50,000 people all year round.

state government, and local government ownerships. The dummy variable Private represents the private ownership type and the dummy Other includes the Public-Private co-ownership and Native American (Hoppe and Schmitz, 2013). Based on NPDWR, we define the dummy variable, Large, to denote a large PWS serving more than 50,000 people. Table 2 illustrates the relationship between PWS ownership type and size. We find that the majority of publicly owned PWSs, or about 98.74 percent, are either medium PWSs that serve 3,300 to 50,000 persons or small PWSs that serve less than 3300 people. In addition, the percentage of large PWSs is higher in publicly owned PWS than in privately owned PWS, 1.26 percent versus 0.06 percent.

The NPDWR has different frequencies of monitoring and degrees of enforcement on PWSs, depending on the types and water sources, that potentially contribute to the difference in violation types observed for publicly and privately owned PWSs. Some PWS types, such as the transient, non-community water systems (TNCWSs), consisting of gas stations, coffee shops, and restaurants, are defined as PWSs in this database but might not operate or be served by any water utilities. We use a dummy variable CWS to indicate if a PWS belongs to a community water system, and the dummy variable NTNCWS indicates if a PWS belongs to a non-transient, noncommunity water system. ${ }^{6}$ The PWS type TNCWS is not specified by any dummy variable and thus is used as a reference level for the other two PWS

6 Office of Water, U.S. EPA (2004) gave the definition of PWS type: community water systems (CWSs) supply water to the same population year-round. It serves at least 25 people at their primary residences or at least 15 residences that are primary residences (for example, municipalities, mobile home park, subdivisions); Non-transient non-community water systems (NTNCWSs) regularly supply water to at least 25 of the same people at least six month per year, but not year-round (for example, schools, factories, office buildings, and hospitals that have their own water systems); Transient non-community water systems (TNCWSs) provide water to 25 or more people for at least 60 days/year but not to the same people and not on a regular basis (for example, gas stations, campgrounds, restaurants with their own water systems). 
type dummies. The dummy variable $G W$ indicates if a PWS has a groundwater source, and the variable $S W$ indicates surface water source.

Our dataset also contains several other dummy variables such as Wholesaler, indicating whether a public water system is a water wholesaler; Daycare, indicating whether it mainly serves daycare centers; a set of dummies indicating primacy agency type of PWS, with Primacy_state being a dummy representing that a state is the primacy agency and Primacy_territory representing Indian tribes being the primacy agency. We use Connections to record the numbers of connections and Population to reflect the population PWS serves. Table 3 provides descriptive statistics for PWS-associated characteristics.

The violation dataset stores violations detected by assessment based on sample results or reviews, including the category and type of contaminants associated with the violation and the time period when the PWS is in the detected violation records. Table 4 shows the frequency of each category of violation. The Monitoring and Reporting (MR) Violation is by far the most frequent violation and represents 74.97 percent of the total violations, followed by Maximum Contaminant Level Violations (or MCL, 9.55 percent) and Treatment Technique Violations (TT, 1.58 percent). Other types of violations only make up a small percentage of the total violations. As a result, we only focus on MR, MCL, and TT violations.

\section{Model Specification}

In this section, we discuss our econometric framework to identify the relationship between PWS ownership and types of violations. We first create a set of dummy variables to present MCL, MR, and TT violations, each taking integer values and representing the counts of certain types of violations that happened in a PWS in any given year. Our violation records include PWSs from 1950 to 2017. However, the data before 1988 is scarce. Therefore, we constructed a panel dataset for each PWS across years and only kept the records after 1988 (dropping about 5 percent of all the records), when the Lead and Copper Rule was enforced, which initiated the time when the majority of violations took place. The violation dataset is then merged with the water system dataset on a PWS-year basis with the water system data. We converted the Population variable into a set of dummy variable Population Categories, i.e., one dummy for each of the population categories with the cutoff points 500,3,300, and 10,000 to better control for the scale of PWSs. Our population categories follow EPA designations in the 2013 National Public Water Systems compliance report, and the same categorization is also used in Allaire et al. (2018).

If a PWS was deactivated before 2017, its violation record would only be kept up to the deactivation year in the panel dataset. Our panel dataset contains $6,384,636$ violation records from 317,587 PWSs. Note that the panel dataset is imbalanced, as some PWSs were deactivated before 2017. Our constructed dataset enables us to track down the violation information for a PWS in a given year. 
Table 3. Water System Characteristics

\begin{tabular}{lcc}
\hline Variables (Binary) & $\mathbf{0}$ & $\mathbf{1}$ \\
\hline CWS & 280,311 & 90,251 \\
NTNCWS & $75.64 \%$ & $24.36 \%$ \\
& 325,706 & 44,856 \\
GW & $87.9 \%$ & $12.1 \%$ \\
SW & 29,235 & 341,327 \\
Wholesaler & $7.89 \%$ & $92.11 \%$ \\
& 341,327 & 29,235 \\
Daycare & $92.11 \%$ & $7.89 \%$ \\
& 367,687 & 2,875 \\
Primacy_state & $99.22 \%$ & $0.78 \%$ \\
Primacy_territory & 353,171 & 17,391 \\
Variable (Continuous) & $95.31 \%$ & $4.69 \%$ \\
Connections & 3,664 & 366,898 \\
Population & $0.99 \%$ & $99.01 \%$ \\
\hline
\end{tabular}

Note: Dummy variables with the value " 1 " indicate corresponding PWS types or characteristics and "0" otherwise. We use the dummy variable CWS to indicate whether a PWS is a community water system, and the dummy variable NTNCWS to indicate whether a PWS is non-transient, non-community water system. The dummy variable $G W$ indicates if a PWS has a groundwater source, and the variable $S W$ indicates whether a PWS uses a surface water source. Our dataset also contains several other dummy variables such as Wholesaler, indicating whether a PWS is a water wholesaler, Daycare, indicating whether a PWS mainly serves a daycare, and a set of dummies indicating PWSs' primacy agency type, state or territory (Indian tribes). We use the continuous variable Connections, which records the numbers of connections.

We specify the following regression model

$$
y_{i t}=\gamma * \text { Ownership }_{i t}+\beta X_{i t}+\eta_{l}+\eta_{t}+\epsilon_{i t},
$$

where $y_{i t}$ is the dependent variable recording the number of occurrences of a certain violation for PWS $i$ in year $t$. As noted before, the types of violations considered in the empirical model include MCL, MR, and TT violations. ${ }^{7}$ The

7 In the Supplementary Appendix, Table A1, we summarize the the distribution of cumulative violation records for public and private PWSs across four violation types. Results show 
Table 4. Water System Violations by Category

\begin{tabular}{lrr}
\hline & Violations by category \\
\hline MCL & \multicolumn{1}{c}{ Freq. } & Percent \\
MON & 218,742 & $9.55 \%$ \\
MR & 32,436 & $1.42 \%$ \\
MRDL & $1,716,717$ & $74.97 \%$ \\
Other & 112 & $<0.01 \%$ \\
RPT & 281,391 & $12.29 \%$ \\
TT & 4,315 & $0.19 \%$ \\
Total & 36,193 & $1.58 \%$ \\
\hline
\end{tabular}

Note: Violation types include Maximum Contaminant Level Violations (MCL), Monitoring (MON), Monitoring and Reporting Violations (MR), Maximum Residual Disinfectant Level (MRDL), Other types of violation (Other), Reporting violation (RPT), and Treatment Technique Violations (TT),

dummy variable Ownership consists of a set of dummy variables, including Public and Other, using the private ownership as the baseline for comparison. The $X_{i t}$ is a set of control variables associated with the PWS. Our control variables include the dummy variables GW, CWS, NTNCWS, Wholesaler, Daycare, Primacy_state, Primacy_territory, Population Categories, and the continuous variable Connections. The $\eta_{l}$ captures the location fixed effects and $\eta_{t}$ includes the set of time fixed effects. The idiosyncratic error term is denoted as $\varepsilon_{i t}$. We specify several models, allowing for different sets of controls. In some specifications, we include the interaction terms of the dummy Ownership and the dummy Large, i.e. Public*Large and Other*Large, which enables us to better control for the correlation between the ownership of and the scale of a PWS, since large PWSs may have more resources to comply with NPDWR (Bhattacharyya et al. 1995). The time fixed effects are at the yearly level and the location fixed effects are controlled at either the state level or the municipal level. ${ }^{8}$

To obtain unbiased estimates, our identification assumption requires

$$
E\left(\text { Ownership }_{i t} * \epsilon_{i t} \mid X_{i t}, \eta_{l}, \eta_{t}\right)=0,
$$

which assumes, after controlling for observed PWS characteristics and unobserved time-invariant location and time fixed effects, confounders do not

\footnotetext{
significant differences in violation occurrence between public and private ownerships based on summary statistics ( $\mathrm{p}<0.001$, using t-test and test of proportions).

8 The "municipal level fixed effects" is a general term used to represent the municipal, township, city, or county level (a single administrative division) fixed effects.
} 
exist that both affect ownership types and the occurrence of violations. To control for these potential confounding factors in our regression model, we use the state level or municipal level fixed effects to control for location heterogeneities in terms of regulations, transaction costs, and economic conditions, although time-varying confounders may still bias our coefficient estimate. The majority of changes of PWS ownership type happened at the turn of the $20^{\text {th }}$ century and during the 1980s (Troesken and Geddes 2003; Arnold 2009; Brubaker 2003), so it is reasonable to assume that there is little influence of time-varying confounders during our data window from 1988 to 2017, when only less than one percent of PWSs experienced an ownership change. We also use a variety of model specifications to assess the robustness of estimation.

\section{Results}

Our first set of regression results is presented in Table 5. The dependent variables are the number of MCL, MR, and TT violations that occurred in a given year for a PWS in Panels A, B, and C, respectively. The location fixed effects, wherever controlled for, are at the state level. Column (1) includes the ownership type dummy variables and the PWS associated control variables defined earlier. We did not include the year or the location fixed effects in Column (1). Column (2) adds the year fixed effects, and Column (3) adds the location fixed effects, in addition to the variables included in Column (1). Column (4) adds both the year and location fixed effects based on Column (1). Column (5) includes interaction terms of the ownership type dummies and the dummy Large, i.e., Public*Large and Other* Large, with year and location fixed effects. Panel A in Table 5 suggests that the publicly owned PWSs commit significantly more MCL violations compared to privately owned PWSs, and the estimates for the dummy Public decrease from 0.00984 to 0.00453 as we add more controls from Column (1) to Column (5). The largest decrease appears from Column (2) to (3), where the coefficient changes from 0.0083 to 0.00534 , suggesting that location fixed effects explain a large amount of variations in the MCL violations. As expected, our results also suggest that large PWSs commit significantly fewer MCL violations. In addition, the interaction effect of Public*Large in Column (5) of Panel A is significant, suggesting that the difference between public and private ownership is further moderated by the scale of the PWSs.

Panel B of Table 5 presents the regression results of the MR violation. Our results consistently show the publicly owned PWSs commit significantly fewer MR violations with the coefficient ranges from -0.085 to -0.095 compared to privately owned PWSs. One possible explanation is that privately owned PWSs might not submit monitored samples to their primacy agencies and intentionally commit MR violations to avoid more expensive MCL violations when water quality issues arise with the PWS water facility or treatment process. The estimates for Large are not consistent across all 
Table 5. Regression Results of Violation Occurrence: State Fixed Effects

\begin{tabular}{|c|c|c|c|c|c|}
\hline & Column (1) & Column (2) & Column (3) & Column (4) & Column (5) \\
\hline \multicolumn{6}{|c|}{ Panel A: MCL Violation } \\
\hline \multirow[t]{2}{*}{ Public } & $0.00984^{* * *}$ & $0.00883^{* * *}$ & $0.00534^{* * *}$ & $0.00464^{* * *}$ & $0.00453^{* * *}$ \\
\hline & $(0.000360)$ & $(0.000358)$ & $(0.000367)$ & $(0.000364)$ & $(0.000365)$ \\
\hline \multirow[t]{2}{*}{ Other } & $-0.00345^{* * *}$ & $-0.00134^{*}$ & $0.00174^{*}$ & $0.00422^{* * *}$ & $0.00418^{* * *}$ \\
\hline & $(0.000672)$ & $(0.000668)$ & $(0.000728)$ & $(0.000724)$ & $(0.000725)$ \\
\hline \multirow[t]{2}{*}{ Large } & $-0.0411^{* * *}$ & $-0.0455^{* * *}$ & $-0.0338^{* * *}$ & $-0.0385^{* * *}$ & $-0.0628^{* * *}$ \\
\hline & $(0.00205)$ & $(0.00204)$ & $(0.00205)$ & $(0.00204)$ & $(0.00550)$ \\
\hline \multirow[t]{2}{*}{ Public*Large } & & & & & $0.0278^{* * *}$ \\
\hline & & & & & $(0.00584)$ \\
\hline \multirow[t]{2}{*}{ Other*Large } & & & & & 0.0276 \\
\hline & & & & & $(0.0179)$ \\
\hline \multirow[t]{2}{*}{ Constant } & $0.0562^{* * *}$ & $0.0308^{* * *}$ & $0.0427^{* * *}$ & $0.0177^{* * *}$ & $0.0177^{* * *}$ \\
\hline & $(0.00188)$ & $(0.00196)$ & $(0.00194)$ & $(0.00201)$ & $(0.00201)$ \\
\hline $\mathrm{N}$ & 6384636 & 6384636 & 6384636 & 6384636 & 6384636 \\
\hline \multicolumn{6}{|c|}{ Panel B: MR Violation } \\
\hline \multirow[t]{2}{*}{ Public } & $-0.0850^{* * *}$ & $-0.0922^{* * *}$ & $-0.0889^{* * *}$ & $-0.0937^{* * *}$ & $-0.0947^{* * *}$ \\
\hline & $(0.00374)$ & $(0.00373)$ & $(0.00380)$ & $(0.00379)$ & $(0.00380)$ \\
\hline \multirow[t]{2}{*}{ Other } & $0.356^{* * *}$ & $0.374^{* * *}$ & $0.0647^{* * *}$ & $0.0848^{* * *}$ & $0.0849^{* * *}$ \\
\hline & $(0.00698)$ & $(0.00696)$ & $(0.00756)$ & $(0.00753)$ & $(0.00754)$ \\
\hline \multirow[t]{2}{*}{ Large } & 0.00262 & -0.0292 & $0.0685^{* *}$ & 0.0352 & $-0.170^{* *}$ \\
\hline & & & & & Continued \\
\hline
\end{tabular}


Table 5. Continued

\begin{tabular}{|c|c|c|c|c|c|}
\hline & Column (1) & Column (2) & Column (3) & Column (4) & Column (5) \\
\hline & $(0.0213)$ & $(0.0213)$ & $(0.0213)$ & $(0.0213)$ & $(0.0572)$ \\
\hline \multirow[t]{2}{*}{ Public*Large } & & & & & $0.238^{* * *}$ \\
\hline & & & & & $(0.0608)$ \\
\hline \multirow[t]{2}{*}{ Other*Large } & & & & & 0.0317 \\
\hline & & & & & $(0.186)$ \\
\hline \multirow[t]{2}{*}{ Constant } & $0.622^{* * *}$ & $0.398^{* * *}$ & $0.789 * * *$ & $0.571^{* * *}$ & $0.571^{* * *}$ \\
\hline & $(0.0196)$ & $(0.0204)$ & $(0.0201)$ & $(0.0209)$ & $(0.0209)$ \\
\hline $\mathrm{N}$ & 6384636 & 6384636 & 6384636 & 6384636 & 6384636 \\
\hline \multicolumn{6}{|c|}{ Panel C: TT Violation } \\
\hline \multirow[t]{2}{*}{ Public } & $0.00200^{* * *}$ & $0.00184^{* * *}$ & $0.00113^{* * *}$ & $0.00102^{* * *}$ & $0.000964^{* * *}$ \\
\hline & $(0.000164)$ & $(0.000164)$ & $(0.000168)$ & $(0.000168)$ & $(0.000168)$ \\
\hline \multirow[t]{2}{*}{ Other } & $0.00216^{* * *}$ & $0.00247^{* * *}$ & $0.00324^{* * *}$ & $0.00362^{* * *}$ & $0.00362^{* * *}$ \\
\hline & $(0.000307)$ & $(0.000307)$ & $(0.000333)$ & $(0.000333)$ & $(0.000334)$ \\
\hline \multirow[t]{2}{*}{ Large } & $-0.0101^{* * *}$ & $-0.0108^{* * *}$ & $-0.00765^{* * *}$ & $-0.00845^{* * *}$ & $-0.0201^{* * *}$ \\
\hline & $(0.000939)$ & $(0.000938)$ & $(0.000941)$ & $(0.000940)$ & $(0.00253)$ \\
\hline \multirow[t]{2}{*}{ Public*Large } & & & & & $0.0135^{* * *}$ \\
\hline & & & & & $(0.00269)$ \\
\hline \multirow[t]{2}{*}{ Other*Large } & & & & & 0.00239 \\
\hline & & & & & $(0.00823)$ \\
\hline \multirow[t]{2}{*}{ Constant } & $0.0312^{* * *}$ & $0.0260^{* * *}$ & $0.0272^{* * *}$ & $0.0221^{* * *}$ & $0.0220^{* * *}$ \\
\hline & $(0.000860)$ & $(0.000899)$ & $(0.000888)$ & $(0.000926)$ & $(0.000926)$ \\
\hline
\end{tabular}


Controls

Yes
Yes

Yes
Yes

Yes
Yes

Yes

Yes

Location Fixed Effects

Yes

Notes: *** indicates $\mathrm{P}<0.001,{ }^{* *}$ indicates $\mathrm{P}<0.05$, and ${ }^{*}$ indicates $\mathrm{P}<0.1$. Standard errors are in the parentheses below the estimated coefficients. For Panels $\mathrm{A}, \mathrm{B}$, and C, the dependent variables are the number of MCL, MR, or TT violations committed by a public water system in a given year, respectively. The Public stands for the public ownership type; Other represents the other ownership type; Large stands for large PWS, Public*Large stands for large publicly owned PWS, and Other*Large stands for large PWS with the ownership type "Other." Column (1) includes the ownership type dummy variables, Public and Other, and control variables do not include the year or the location fixed effects. Column (2) adds the year fixed effects, and Column (3) adds the location fixed effects, in addition to the variables included in Column (1). Column (4) adds both the year and location fixed effects based on Column (1). Column (5) includes interaction terms of the ownership type dummies and the dummy Large, i.e., Public ${ }^{*}$ Large and Other $^{*}$ Large, with both year and location fixed effects. Location fixed effects controlled for are at the state level. 
specifications and are negative and significant at a 5 percent level in Column (5) when interaction terms such as Public*Large are included.

Panel C presents the regression results of the TT violation. Regression results suggest that publicly owned PWSs commit significantly more TT violations compared to privately owned PWSs, and the estimated coefficient ranges from 0.002 to 0.000964 . Adding more controls gradually reduces the magnitude of the coefficient. Table 5 provides consistent evidence that privately owned PWSs commit more MR violations while reducing potential MCL and TT violations.

Table 6 is similar to Table 5, except we use a stronger location control, the municipality fixed effects instead of the state fixed effects. Panel A shows that publicly owned PWSs commit significantly more MCL violations than privately owned PWSs. Panel B suggests that the publicly owned PWSs commit significantly fewer MR violations compared to privately owned PWSs, and panel $\mathrm{C}$ shows that publicly owned PWSs commit slightly more TT violations than privately owned PWSs. Table 6 reconfirms that coefficients estimated for treatment variable Public are robust after controlling for different levels of location fixed effects.

Comparing Tables 5 and 6, we find that coefficient estimates for Public become smaller after controlling for the municipality fixed effects instead of the state fixed effects, indicating that municipality fixed effects explain a larger amount of variations for the MCL and TT violations. In addition, we find that the interaction term between Public and Large is smaller for MCL and TT violations and no longer significant for MR violations after controlling for municipality fixed effects, implying that large publicly owned PWSs may commit more MCL and TT violations than privately owned and small or medium PWSs regardless of the degree of location heterogeneities controlled. This result may also be related to the underreporting behavior of privately owned and small or medium PWSs, since large publicly owned PWSs are not significantly committing more MR violations when controlling for municipality fixed effects, as shown in Panel B of Table 6.

Table 7 presents the regression results using the number of Health-Related violations of a PWS in a given year as the dependent variable. Panel A controls for the state-level fixed effects and Panel B controls for the municipal-level fixed effects. Interestingly, we find the publicly owned utilities incur significantly more Health-Related violations compared to privately owned utilities. While a large utility generally commits a lower HealthRelated violation, the interaction term Public*Large is positively significant. Adding more controls reduces the magnitude of coefficient estimates, and using a municipality-level fixed effects model further reduces the magnitude, though the coefficient is highly significant across all specifications. We only keep several key variables in the tables and leave the full model estimation results to the Supplementary Appendix, Tables A2 and A3. Based on the full model, we find the community water system (CWS) significantly increases all types of violations; the non-transient, non-community water system 
Table 6. Regression Results of Violation Occurrence: Municipality Fixed Effects

\begin{tabular}{|c|c|c|c|c|c|}
\hline & Column (1) & Column (2) & Column (3) & Column (4) & Column (5) \\
\hline \multicolumn{6}{|c|}{ Panel A: MCL Violation } \\
\hline \multirow[t]{2}{*}{ Public } & $0.00984^{* * *}$ & $0.00883^{* * *}$ & $0.00424^{* * *}$ & $0.00335^{* * *}$ & $0.00328^{* * *}$ \\
\hline & $(0.000360)$ & $(0.000358)$ & $(0.000406)$ & $(0.000403)$ & $(0.000404)$ \\
\hline \multirow[t]{2}{*}{ Other } & $-0.00345^{* * *}$ & $-0.00134^{*}$ & $-0.00269^{* * *}$ & -0.000170 & -0.000177 \\
\hline & $(0.000672)$ & $(0.000668)$ & $(0.000773)$ & $(0.000769)$ & $(0.000769)$ \\
\hline \multirow[t]{2}{*}{ Large } & $-0.0411^{* * *}$ & $-0.0455^{* * *}$ & $-0.0293^{* * *}$ & $-0.0348^{* * *}$ & $-0.0528^{* * *}$ \\
\hline & $(0.00205)$ & $(0.00204)$ & $(0.00221)$ & $(0.00219)$ & $(0.00588)$ \\
\hline \multirow[t]{2}{*}{ Public*Large } & & & & & $0.0206^{* * *}$ \\
\hline & & & & & $(0.00622)$ \\
\hline \multirow[t]{2}{*}{ Other*Large } & & & & & 0.00909 \\
\hline & & & & & $(0.0185)$ \\
\hline \multirow[t]{2}{*}{ Constant } & $0.0562^{* * *}$ & $0.0308^{* * *}$ & $0.0180^{* * *}$ & $-0.00997^{* *}$ & $-0.00998^{* *}$ \\
\hline & $(0.00188)$ & $(0.00196)$ & $(0.00330)$ & $(0.00333)$ & $(0.00333)$ \\
\hline $\mathrm{N}$ & 6384636 & 6384636 & 6384636 & 6384636 & 6384636 \\
\hline \multicolumn{6}{|c|}{ Panel B: MR Violation } \\
\hline \multirow[t]{2}{*}{ Public } & $-0.0850^{* * *}$ & $-0.0922^{* * *}$ & $-0.0927^{* * *}$ & $-0.0989^{* * *}$ & $-0.0995^{* * *}$ \\
\hline & $(0.00374)$ & $(0.00373)$ & $(0.00426)$ & $(0.00424)$ & $(0.00425)$ \\
\hline \multirow[t]{2}{*}{ Other } & $0.356^{* * *}$ & $0.374^{* * *}$ & $0.157^{* * *}$ & $0.178^{* * *}$ & $0.178^{* * *}$ \\
\hline & $(0.00698)$ & $(0.00696)$ & $(0.00811)$ & $(0.00808)$ & $(0.00809)$ \\
\hline \multirow[t]{2}{*}{ Large } & 0.00262 & -0.0292 & $0.0918^{* * *}$ & $0.0523^{*}$ & -0.0484 \\
\hline & $(0.0213)$ & $(0.0213)$ & $(0.0231)$ & $(0.0231)$ & $(0.0618)$ \\
\hline \multirow[t]{2}{*}{ Public*Large } & & & & & 0.121 \\
\hline & & & & & $(0.0654)$ \\
\hline
\end{tabular}


Table 6. Continued

\begin{tabular}{|c|c|c|c|c|c|}
\hline & Column (1) & Column (2) & Column (3) & Column (4) & Column (5) \\
\hline \multirow[t]{2}{*}{ Other*Large } & & & & & -0.315 \\
\hline & & & & & $(0.195)$ \\
\hline \multirow[t]{2}{*}{ Constant } & $0.622^{* * *}$ & $0.398^{* * *}$ & $0.416^{* * *}$ & $0.173^{* * *}$ & $0.173^{* * *}$ \\
\hline & $(0.0196)$ & $(0.0204)$ & $(0.0346)$ & $(0.0350)$ & $(0.0350)$ \\
\hline $\mathrm{N}$ & 6384636 & 6384636 & 6384636 & 6384636 & 6384636 \\
\hline \multicolumn{6}{|l|}{ Panel C: TT Violation } \\
\hline \multirow[t]{2}{*}{ Public } & $0.00200^{* * *}$ & $0.00184^{* * *}$ & $0.000691^{* * *}$ & $0.000553^{* *}$ & $0.000505^{* *}$ \\
\hline & $(0.000164)$ & $(0.000164)$ & $(0.000186)$ & $(0.000186)$ & $(0.000186)$ \\
\hline \multirow[t]{2}{*}{ Other } & $0.00216^{* * *}$ & $0.00247^{* * *}$ & 0.000634 & $0.00102^{* *}$ & $0.00102^{* *}$ \\
\hline & $(0.000307)$ & $(0.000307)$ & $(0.000354)$ & $(0.000354)$ & $(0.000355)$ \\
\hline \multirow[t]{2}{*}{ Large } & $-0.0101^{* * *}$ & $-0.0108^{* * *}$ & $-0.00635^{* * *}$ & $-0.00729^{* * *}$ & $-0.0185^{* * *}$ \\
\hline & $(0.000939)$ & $(0.000938)$ & $(0.00101)$ & $(0.00101)$ & $(0.00271)$ \\
\hline \multirow[t]{2}{*}{ Public*Large } & & & & & $0.0129^{* * *}$ \\
\hline & & & & & $(0.00287)$ \\
\hline \multirow[t]{2}{*}{ Other*Large } & & & & & 0.00391 \\
\hline & & & & & $(0.00853)$ \\
\hline \multirow[t]{2}{*}{ Constant } & $0.0312^{* * *}$ & $0.0260^{* * *}$ & $0.0236^{* * *}$ & $0.0180^{* * *}$ & $0.0180^{* * *}$ \\
\hline & $(0.000860)$ & $(0.000899)$ & $(0.00151)$ & $(0.00153)$ & $(0.00153)$ \\
\hline $\mathrm{N}$ & 6384636 & 6384636 & 6384636 & 6384636 & 6384636 \\
\hline Controls & Yes & Yes & Yes & Yes & Yes \\
\hline Time Fixed Effects & & Yes & & Yes & Yes \\
\hline Location Fixed Effects & & & Yes & Yes & Yes \\
\hline
\end{tabular}

Notes: *** indicates $\mathrm{P}<0.001$, ** indicates $\mathrm{P}<0.05$, and * indicates $\mathrm{P}<0.1$. Standard errors are in the parentheses below the estimated coefficients. For Panels $\mathrm{A}, \mathrm{B}$, and $\mathrm{C}$, the dependent variables are the number of MCL, MR, or TT violations committed by a PWS in a given year, respectively. Location fixed effects controlled for are at the municipal level. 
Table 7. Regression Results of Health-Related Violation

\begin{tabular}{|c|c|c|c|c|c|}
\hline & Column (1) & Column (2) & Column (3) & Column (4) & Column (5) \\
\hline \multicolumn{6}{|c|}{ Panel A: Health-Related Violation, State Fixed Effects } \\
\hline \multirow[t]{2}{*}{ Public } & $0.0119^{* * *}$ & $0.0107^{* * *}$ & $0.00649^{* * *}$ & $0.00567^{* * *}$ & $0.00551^{* * *}$ \\
\hline & $(0.000407)$ & $(0.000404)$ & $(0.000414)$ & $(0.000412)$ & $(0.000413)$ \\
\hline \multirow[t]{2}{*}{ Other } & -0.00128 & 0.00114 & $0.00498^{* * *}$ & $0.00784^{* * *}$ & $0.00780^{* * *}$ \\
\hline & $(0.000759)$ & $(0.000755)$ & $(0.000823)$ & $(0.000818)$ & $(0.000819)$ \\
\hline \multirow[t]{2}{*}{ Large } & $-0.0511^{* * *}$ & $-0.0564^{* * *}$ & $-0.0415^{* * *}$ & $-0.0469^{* * *}$ & $-0.0830^{* * *}$ \\
\hline & $(0.00232)$ & $(0.00231)$ & $(0.00232)$ & $(0.00231)$ & $(0.00621)$ \\
\hline \multirow[t]{2}{*}{ Public*Large } & & & & & $0.0414^{* * *}$ \\
\hline & & & & & $(0.00660)$ \\
\hline \multirow[t]{2}{*}{ Other*Large } & & & & & 0.0300 \\
\hline & & & & & $(0.0202)$ \\
\hline \multirow[t]{2}{*}{ Constant } & $0.0874^{* * *}$ & $0.0568^{* * *}$ & $0.0699 * * *$ & $0.0398^{* * *}$ & $0.0398^{* * *}$ \\
\hline & $(0.00213)$ & $(0.00221)$ & $(0.00219)$ & $(0.00227)$ & $(0.00227)$ \\
\hline $\mathrm{N}$ & 6384636 & 6384636 & 6384636 & 6384636 & 6384636 \\
\hline \multicolumn{6}{|c|}{ Panel B: Health-Related Violation, Municipality Fixed Effects } \\
\hline \multirow[t]{2}{*}{ Public } & $0.0119^{* * *}$ & $0.0107^{* * *}$ & $0.00495^{* * *}$ & $0.00392^{* * *}$ & $0.00379^{* * *}$ \\
\hline & $(0.000407)$ & $(0.000404)$ & $(0.000458)$ & $(0.000455)$ & $(0.000456)$ \\
\hline \multirow[t]{2}{*}{ Other } & -0.00128 & 0.00114 & $-0.00205^{*}$ & 0.000861 & 0.000853 \\
\hline & $(0.000759)$ & $(0.000755)$ & $(0.000873)$ & $(0.000868)$ & $(0.000868)$ \\
\hline \multirow[t]{2}{*}{ Large } & $-0.0511^{* * *}$ & $-0.0564^{* * *}$ & $-0.0357^{* * *}$ & $-0.0421^{* * *}$ & $-0.0713^{* * *}$ \\
\hline & $(0.00232)$ & $(0.00231)$ & $(0.00249)$ & $(0.00248)$ & $(0.00664)$ \\
\hline
\end{tabular}


Table 7. Continued

\begin{tabular}{|c|c|c|c|c|c|}
\hline & Column (1) & Column (2) & Column (3) & Column (4) & Column (5) \\
\hline \multirow[t]{2}{*}{ Public*Large } & & & & & $0.0336^{* * *}$ \\
\hline & & & & & $(0.00702)$ \\
\hline \multirow[t]{2}{*}{ Other*Large } & & & & & 0.0130 \\
\hline & & & & & $(0.0209)$ \\
\hline \multirow[t]{2}{*}{ Constant } & $0.0874^{* * *}$ & $0.0568^{* * *}$ & $0.0415^{* * *}$ & $0.00796^{*}$ & $0.00795^{*}$ \\
\hline & $(0.00213)$ & $(0.00221)$ & $(0.00373)$ & $(0.00376)$ & $(0.00376)$ \\
\hline $\mathrm{N}$ & 6384636 & 6384636 & 6384636 & 6384636 & 6384636 \\
\hline Controls & Yes & Yes & Yes & Yes & Yes \\
\hline Time Fixed Effects & & Yes & & Yes & Yes \\
\hline Location Fixed Effects & & & Yes & Yes & Yes \\
\hline
\end{tabular}

Notes: $* * *$ indicates $\mathrm{P}<0.001,{ }^{* *}$ indicates $\mathrm{P}<0.05$ and $*$ indicates $\mathrm{P}<0.1$. Standard errors are in the parentheses below the estimated coefficients. For Panels $\mathrm{A}$ and $\mathrm{B}$, the dependent variables are the number of Health-Related violations committed by a PWS in a given year, respectively. 
(NTNCWS) also significantly increases all types of violations, compared to the baseline transient non-community water system (TNCWS). In addition, if a PWS has a groundwater (GW) source, the PWS is more likely to incur MCL, TT, and Health-Related violations but less likely to incur MR violations.

Our main results reveal systematic differences between the public and private utilities on the types of violations. We find strong evidence that publicly owned utilities are more likely to commit costly violations such as MCL and TT, and privately owned utilities are more likely to commit less costly MR violations. Our results are consistent with the story that privately owned utilities may intentionally commit MR violations instead of MCL and TT violations since the MCL and TT violations are more costly to resolve. We also find that public utilities are more likely to commit Health-Related violations. However, since privately owned utilities commit more MR violations, some HealthRelated violations are less likely to be detected due to more MR violations for private utilities. We do not believe our results indicate drinking water provided by the public utility is less safe compared to water provided by the private utility. Due to data limitations, we are unable to fully explore this hypothesis. Future research can combine drinking water-related disease with the drinking water source to determine whether there is a systematic difference in terms of drinking water-related disease between public and private drinking water utilities. We also use a Tobit model where the dependent variable is the cumulative violation records, as the dependent variable is highly skewed to zero. The regression results for the Tobit model are provided in the Supplementary Appendix, Table A4. Our main conclusions remain the same, and the regression results are consistent with fixed effects models on the directions and significance of major coefficients, though the magnitudes of the coefficients are different after we change the dependent variable.

\section{Robustness check with the CWS subsample}

The PWSs consist of the community (CWS) and non-community systems. The non-community system further consists of the transient (TNCWS) and nontransient (NTNCWS) system. Since NTNCWSs contain schools, factories, office buildings, and hospitals that have their own water systems, and TNCWSs contain gas stations, resorts, restaurants, and motels with their own systems (Centers for Disease Control and Prevention 2014), NTNCWSs and TNCWSs might not be operating or be served by any actual water utilities. These two types of PWSs might not sell water as their main goal of the operation and not have the complete infrastructure and management system as regular water utilities do. As a result, they might have different incentives and operation practices compared to actual water utilities. For example, a coffee shop might apply a commercial water filter, which might not be as effective in treating water as the technique used in a water utility, while the coffee shop manager cares about their water service quality as much as a publicly 
Table 8. Regression Results of Violation Occurrence for the CWS Subsample

\begin{tabular}{|c|c|c|c|c|c|}
\hline & Column (1) & Column (2) & Column (3) & Column (4) & Column (5) \\
\hline \multicolumn{6}{|c|}{ Panel A: MCL Violation } \\
\hline \multirow[t]{2}{*}{ Public } & $0.0220^{* * *}$ & $0.0171^{* * *}$ & $0.0124^{* * *}$ & $0.00812^{* * *}$ & $0.00789^{* * *}$ \\
\hline & $(0.00101)$ & $(0.00100)$ & $(0.00106)$ & $(0.00105)$ & $(0.00105)$ \\
\hline \multirow[t]{2}{*}{ Other } & $0.00646^{* *}$ & $0.00760^{* *}$ & 0.00248 & 0.00367 & 0.00340 \\
\hline & $(0.00244)$ & $(0.00242)$ & $(0.00278)$ & $(0.00276)$ & $(0.00277)$ \\
\hline \multirow[t]{2}{*}{ Large } & $-0.0513^{* * *}$ & $-0.0590^{* * *}$ & $-0.0394^{* * *}$ & $-0.0473^{* * *}$ & $-0.0664^{* * *}$ \\
\hline & $(0.00389)$ & $(0.00385)$ & $(0.00390)$ & $(0.00387)$ & $(0.00933)$ \\
\hline \multirow[t]{2}{*}{ Public*Large } & & & & & $0.0216^{*}$ \\
\hline & & & & & $(0.00975)$ \\
\hline \multirow[t]{2}{*}{ Other*Large } & & & & & 0.0390 \\
\hline & & & & & $(0.0306)$ \\
\hline \multirow[t]{2}{*}{ Constant } & $0.104^{* * *}$ & $0.0526^{* * *}$ & $0.0899^{* * *}$ & $0.0396^{* * *}$ & $0.0398^{* * *}$ \\
\hline & $(0.00415)$ & $(0.00455)$ & $(0.00447)$ & $(0.00483)$ & $(0.00483)$ \\
\hline $\mathrm{N}$ & 1781001 & 1781001 & 1771425 & 1771425 & 1771425 \\
\hline \multicolumn{6}{|c|}{ Panel B: MR Violation } \\
\hline \multirow[t]{2}{*}{ Public } & $-0.0777^{* * *}$ & $-0.117^{* * *}$ & $-0.0657^{* * *}$ & $-0.100^{* * *}$ & $-0.104^{* * *}$ \\
\hline & $(0.0105)$ & $(0.0104)$ & $(0.0109)$ & $(0.0109)$ & $(0.0109)$ \\
\hline \multirow[t]{2}{*}{ Other } & $1.744^{* * *}$ & $1.752^{* * *}$ & $0.199 * * *$ & $0.209^{* * *}$ & $0.209^{* * *}$ \\
\hline & $(0.0252)$ & $(0.0251)$ & $(0.0288)$ & $(0.0286)$ & $(0.0287)$ \\
\hline \multirow[t]{2}{*}{ Large } & -0.0133 & -0.0691 & $0.0862^{*}$ & 0.0281 & $-0.212^{*}$ \\
\hline & $(0.0403)$ & $(0.0400)$ & $(0.0404)$ & $(0.0401)$ & $(0.0967)$ \\
\hline \multirow[t]{2}{*}{ Public*Large } & & & & & $0.279^{* *}$ \\
\hline & & & & & $(0.101)$ \\
\hline
\end{tabular}


Other*Large

Constant

$\mathrm{N}$

Panel C: TT Violation

Public

$0.00494^{* * *}$

(0.000463)

Other

$0.0136^{* * *}$

(0.00111)

Large

$-0.0209^{* * *}$

(0.00178)

Public*Large

Other*Large

$\begin{array}{lc}\text { Constant } & 0.0333^{* * *} \\ & (0.00190) \\ \mathrm{N} & 1781001\end{array}$

Panel D: Health-Related Violation

Public

$0.0270^{* * *}$

$(0.00115)$

Other
$-0.520^{* * *}$

(0.0472)

1781001

$0.00414^{* * *}$

(0.000463)

$0.0138^{* * *}$

(0.00111)

$-0.0222^{* * *}$

(0.00178)
$1.135^{* * *}$

(0.0462)

1771425

$0.00250^{* * *}$

(0.000484)

$0.0130^{* * *}$

(0.00128)

$-0.0169^{* * *}$

(0.00179)

$-0.00551$

(0.317)

$0.643^{* * *}$

(0.0501)

1771425

(0.0501)

1771425

$0.00180^{* * *}$

(0.000484)

$0.0132^{* * *}$

(0.00128)

$-0.0182^{* * *}$

(0.00179)

$0.00165^{* * *}$

(0.000486)

$0.0132^{* * *}$

(0.00128)

$-0.0295^{* * *}$

(0.00431)

$0.0130^{* *}$

(0.00450)

0.00122

(0.0141)

$0.0157^{* * *}$

(0.00223)

1771425

1781001

(0.00205)

1771425

$0.0157^{* * *}$

(0.00223)

1771425

$0.0150^{* * *}$

(0.00120)

$0.0155^{* * *}$

$0.00994^{* * *}$

$0.00956^{* * *}$

$(0.00119)$

(0.00120)

$(0.00114)$

$0.0169^{* * *}$

$0.0167^{* * *}$

(0.00275)

(0.00317)

(0.00314)

(0.00315) 
Table 8. Continued

\begin{tabular}{|c|c|c|c|c|c|}
\hline & Column (1) & Column (2) & Column (3) & Column (4) & Column (5) \\
\hline \multirow[t]{2}{*}{ Large } & $-0.0722^{* * *}$ & $-0.0812^{* * *}$ & $-0.0562^{* * *}$ & $-0.0656^{* * *}$ & $-0.0959 * * *$ \\
\hline & $(0.00442)$ & $(0.00438)$ & $(0.00444)$ & $(0.00440)$ & $(0.0106)$ \\
\hline \multirow[t]{2}{*}{ Public*Large } & & & & & $0.0347^{* *}$ \\
\hline & & & & & $(0.0111)$ \\
\hline \multirow[t]{2}{*}{ Other*Large } & & & & & 0.0402 \\
\hline & & & & & $(0.0348)$ \\
\hline \multirow[t]{2}{*}{ Constant } & $0.138^{* * *}$ & $0.0730^{* * *}$ & $0.118^{* * *}$ & $0.0553^{* * *}$ & $0.0555^{* * *}$ \\
\hline & $(0.00472)$ & $(0.00517)$ & $(0.00508)$ & $(0.00549)$ & $(0.00550)$ \\
\hline $\mathrm{N}$ & 1781001 & 1781001 & 1771425 & 1771425 & 1771425 \\
\hline Controls & Yes & Yes & Yes & Yes & Yes \\
\hline Time Fixed Effects & & Yes & & Yes & Yes \\
\hline Location Fixed Effects & & & Yes & Yes & Yes \\
\hline
\end{tabular}

Notes: $^{* * *}$ indicates $\mathrm{P}<0.001,{ }^{* *}$ indicates $\mathrm{P}<0.05$ and ${ }^{*}$ indicates $\mathrm{P}<0.1$. Standard errors are in the parentheses below the estimated coefficients. 
owned PWS manager does, since their quality of water determines the quality of their coffee and guarantees their food security. The percentages of public and private PWSs in the community and non-community systems are summarized in Table A5. We find the publicly owned CWSs represents 40.72 percent of the facilities in the CWS subsample, a much higher percentage compared to the full sample of 21.04 percent.

To control for the systematic differences in incentives and operation practices between CWSs and non-community systems, we run additional regression with the CWS subsample only. Regression results are presented in Table 8, suggesting that publicly owned PWSs commit significantly more MCL, TT, and Health-Related violations but fewer MR violations than privately owned PWSs, after we control for the time and location fixed effects. Therefore, when restricting our analysis to only the CWSs, our main conclusions still hold. Our regression results using the CWS subsample further support our hypothesis that privately owned PWSs may commit more MR violations while preventing potential MCL, TT, and Health-Related violations.

\section{Conclusion}

In this article, we review the National Primary Drinking Water Regulation and compare different drinking water regulations as well as their violation determinations. We find that MCL and TT violations are associated with high compliance costs and violation penalties, which may lead PWSs to choose different compliance actions. We then construct a comprehensive violation dataset based on the U.S. EPA's Safe Drinking Water Information System to conduct our empirical analyses. We find that publicly owned PWSs commit significantly more MCL and TT violations but fewer MR violations compared to privately owned PWS. Our results are robust to different model specifications, including controlling for potential interaction effects, yearly fixed effects, and location fixed effects at the state or municipal level.

We assume that given all observed PWS characteristics, year fixed effects, and location fixed effects, there are no other confounding factors that both affect PWS ownership determination and PWS water supply quality violations. Based on this assumption, our analyses show that publicly owned PWSs still commit significantly more MCL, TT, and Health-Related violations than privately owned PWSs. Our article does not explore the mechanism behind the observed differences explicitly. However, empirical evidence suggests potential strategic or underreporting behaviors for privately owned utilities. We suspect that PWS operators may choose not to submit the required sample when the operators know that there is something wrong with their water system facilities or treatment process. Therefore, privately owned PWSs can avoid fixing potential MCL and TT violations, both of which involve more costly penalty and stringent enforcement actions, while committing less costly MR violations. We have not considered the price difference explicitly between the public and private PWSs. The local economic condition might 
lead to municipalities outsourcing their water utilities to private parties, which in turn leads to high water prices and better service quality. Our location fixed effects can control for the heterogeneity in local economic conditions. Future studies with additional price information could explore on whether water price is a potential mechanism through which the ownership affects different types of violations rates.

Our regression analyses confirm that the difference between public and private PWSs is highly significant across all specifications. We also show that the estimates for the dummy Public are smaller when we control for municipality fixed effects instead of state fixed effects, which suggests that finer location heterogeneities explain a substantial amount of the variation of MCL, TT, and Health-Related violations. Our results also have important implications for distributing government and private funding to improve drinking water infrastructure. The government implements various programs, such as the Drinking Water State Revolving Fund, Community Development Block Grant Program, and Small Community Water Infrastructure Exchange to improve drinking water quality. Our regression results show that the efforts to improve municipal water supply quality should take the utility ownership into consideration and focus on dealing with the location disadvantages, such as the poor financial situation of local government, to increase the efficiency of current funding programs.

\section{Funding Sources}

This material is based upon work partially supported by the USDA-NIFA through Agricultural Experiment Station (AES) and/or Cooperative Extension (CE) at the University of Rhode Island (URI) under RI0018-W4133, No. 1014661, as well as the University of Connecticut (UCONN) Agricultural Experiment Station in Storrs, CT.

\section{Supplementary material}

The supplementary material for this article can be found at https://doi.org/10. 1017/age.2020.4.

\section{References}

Allaire, Maura, Haowei Wu, and Upmanu Lall. 2018. "National Trends in Drinking Water Quality Violations." PNAS 115 (9): 2078-2083.

Arnold, Craig A. 2009. "Water Privatization Trends in the United States: Human Rights, National Security, and Public Stewardship." William \& Mary Environmental Law and Policy Review 3 (33): Article 4. http://scholarship.law.wm.edu/wmelpr/vol33/iss3/4.

Bakker, Karen. 2014. "The Business of Water: Market Environmentalism in the Water Sector." Annual Review of Environment and Resources 39: 469-494. 
Balazs, Carolina L., Rachel Morello-Frosch, Alan E. Hubbard, and Isha Ray. 2011. "Social Disparities in Nitrate-Contaminated Drinking Water in California's San Joaquin Valley." Environmental Health Perspectives 119 (12): Article 509.

- 2012. "Environmental Justice Implications of Arsenic Contamination in California's San Joaquin Valley: A Cross-Sectional, Cluster-Design Examining Exposure and Compliance in Community Drinking Water Systems." Environmental Health 11 (1): Article 84.

Bhattacharyya, Arunava, Thomas R. Harris, Rangesan Narayanan, and Kambiz Raffiee. 1995. "Specification and Estimation of the Effect of Ownership on the Economic Efficiency of the Water Utilities." Regional Science and Urban Economics 25 (6): 759-84.

Brubaker, Elizabeth. 2003. "Revisiting Water and Wastewater Utility Privatization." Presented at "Public Goals, Private Means" Research Colloquium, Faculty of Law, University of Toronto, October 3, 2003.

Butler, Lindsey J., Madeleine K. Scammell, and Eugene B. Benson. 2016. "The Flint, Michigan, Water Crisis: A Case Study in Regulatory Failure and Environmental Injustice." Environmental Justice 9 (4): 93-97.

Byrnes, Patricia, Shawna Grosskopf, and Kathy Hayes. 1986. "Efficiency and Ownership: Further Evidence." The Review of Economics and Statistics 68 (2): 337-41.

Centers for Disease Control and Prevention. 2014. Public Water Systems. https://www.cdc. gov/healthywater/drinking/public/index.html.

Chong, Eshien, Freddy Huet, Stéphane Saussier, and Faye Steiner. 2006. "Public-Private Partnerships and Prices: Evidence from Water Distribution in France." Review of Industrial Organization (2006) 29:149-169.

Crain, W. Mark, and Asghar Zardkoohi. 1978. "A Test of the Property-Rights Theory of the Firm: Water Utilities in the United States." The Journal of Law \& Economics 21 (2): 395-408.

Environmental Justice Coalition for Water. 2005. Thirsty for Justice: A People's Blueprint for California Water. Oakland: EJCW

Feigenbaum, Susan, and Ronald Teeples. 1983. "Public Versus Private Water Delivery: A Hedonic Cost Approach." The Review of Economics and Statistics 65 (4): 672-678.

Food \& Water Watch. 2015. "Water Privatization: Facts and Figures." https://www. foodandwaterwatch.org/insight/water-privatization-facts-and-figures.

García-Valiñas, María de los Ángeles, Francisco González-Gómez, and Andres J. Picazo-Tadeo. 2013. "Is the Price of Water for Residential Use Related to Provider Ownership? Empirical Evidence from Spain." Utilities Policy 24, no. C: 59-69.

Guerrero-Preston, Rafael, José Norat, Mario Rodríguez, Lydia Santiago, and Erick Suárez. 2008. "Determinants of Compliance with Drinking Water Standards in Rural Puerto Rico between 1996 and 2000: A Multilevel Approach." Puerto Rico Health Science Journal 27(3): 229-235.

Hoppe, Eva I., and Patrick W. Schmitz. 2013. "Public-Private Partnerships Versus Traditional Procurement: Innovation Incentives and Information Gathering." The RAND Journal of Economics 44, no. 1: 56-74.

Megginson, William L., and Jeffry M. Netter. 2001. "From State to Market: A Survey of Empirical Studies on Privatization." Journal of Economic Literature 39 (2): 321-89.

National Research Council. 2002. Privatization of Water Services in the United States: An Assessment of Issues and Experience. Washington, DC: The National Academies Press.

Office of Enforcement and Compliance Assurance, U.S. Environmental Protection Agency. 2013. Providing safe drinking water in America: 2013 National Public Water Systems Compliance Report. EPA Document 305R15001.

Office of Water (4606), U.S. Environmental Protection Agency. 2004. Understanding the Safe Drinking Water Act, EPA 816-F-04-030.

Pilley, Amy K., Sandra Jacquez, Robert Buckingham, Satya P. Rao, Kiran Sapkota, Sara Kumar Rai, Ashley Graboski-Bauer, and Thriveni Reddy. 2009. "Prevalence of Arsenic Contaminated Drinking Water in Southern New Mexico Border Colonias." Conference: 
137st American Public Health Association Annual Meeting and Exposition. https://apha. confex.com/apha/137am/webprogram/Paper204703.html.

Porcher, Simon. 2017. "The 'Hidden Costs' of Water Provision: New Evidence from the Relationship between Contracting-Out and Price in French Water Public Services." Utilities Policy 48 (2017): 166-175.

Rahman, Tauhidur, Mini Kohli, Sharon B. Megdal, Satheesh V. Aradhyula, and Jackie Moxley. 2010. "Determinants of Environmental Noncompliance by Public Water Systems." Contemporary Economic Policy 28 (2): 264-274.

Renner, Rebecca. 2004. "Plumbing the Depths of D.C.'s Drinking Water Crisis." Environmental Science \& Technology 38 (12): 224A-227A.

Rubin, Scott J. 2013. "Evaluating Violations of Drinking Water Regulations." Journal American Water Works Association 105 (3): 137-147.

Saal, David S., and David Parker. 2001. "Productivity and Price Performance in the Privatized Water and Sewerage Companies of England and Wales." Journal of Regulatory Economics 20 (1): 61-90.

Suárez-Varela, Marta, María de los Ángeles García-Valiñas, Francisco González-Gómez, and Andrés J. Picazo-Tadeo. 2017. "Ownership and Performance in Water Services Revisited: Does Private Management Really Outperform Public?" Water Resources Management 31 (8): 2355-2373.

Teeples, Ronald, David Glyer. 1987. "Cost of Water Delivery Systems: Specification and Ownership Effects." The Review of Economics and Statistics 69 (3): 399-408.

Tiemann, Mary. 2017. "Safe Drinking Water Act (SDWA): A Summary of the Act and Its Major Requirements." Congressional Research Service 7-5700.

Troesken, Werner, and Rick Geddes. 2003. "Municipalizing American Waterworks, 18971915." Journal of Law, Economics, \& Organization 19 (2): 373-400.

U.S. Environmental Protection Agency. 1986. Water Supply Guide 27. Date Signed: August 25, 1986.

- 2017. Safe Drinking Water Information System.

- 2017. National Water Quality Inventory: Report to Congress. EPA 841-R-16-011.

U.S. Government Publishing Office. 2019. Electronic Code of Federal Regulations, Part 141, National Primary Drinking Water Regulations. https://www.ecfr.gov/cgi-bin/text-idx?

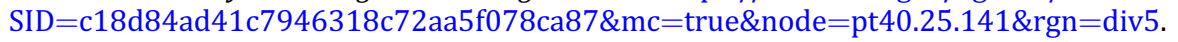

Wait, Isaac W., William Adam Petrie. 2017. "Comparison of Water Pricing for Publicly and Privately Owned Water Utilities in the United States." Water International 42(8): 967-980.

Wallsten, Scott, Katrina Kosec. 2008. "The Effects of Ownership and Benchmark Competition: An Empirical Analysis of U.S. Water Systems." International Journal of Industrial Organization 26 (1): 186-205.

Welch, Alan H., Michael S. Lico, and Jennifer L. Hughes. 1988. "Arsenic in Ground Water of the Western United States." Ground Water 26 (3): 333-347.

Wolff, Gary, and Eric. Hallstein. 2005. Beyond Privatization: Restructuring Water Systems to Improve Performance. Pacific Institute, Oakland, CA. 